\title{
Editorial - Atores Sociais, Formação em Saúde e Quadros Clínicos
}

É com muita alegria que tornamos público o primeiro número do volume onze da Revista Psicologia e Saúde. Estamos particularmente felizes por completar 10 anos de vida em 2019! No segundo semestre de 2009, foi publicado o volume 1, número 1 de nossa querida revista. De lá pra cá, muitos aspectos mudaram, mas não nossas características centrais, quais sejam: refletir a pluralidade do Programa de Pós-Graduação em Psicologia da Universidade Católica Dom Bosco (UCDB) e promover o diálogo de diferentes disciplinas no que tange às relações entre Saúde, cultura e sociedade. Agradecemos imensamente a todos(as) os(as) editores(as) e editores(as) associados(as) que trabalharam por nosso periódico! Sem vocês, nada do que apresentamos hoje seria possível.

Aquelas duas características principais de nossa revista nos parecem claras no número que hoje apresentamos às pessoas que nos leem. Primeiramente, vemos trabalhos com características metodológicas bastante diferentes, desde revisões sistemáticas de literatura, passando por instrumentos de medida, chegando a metodologias claramente qualitativas. Em segundo lugar, temos trabalhos conduzidos por diferentes profissionais, oriundos da Educação Física, Enfermagem, Psicologia, Serviço Social, dentre outros. Assim, reiteramos nosso objetivo de difundir e promover conhecimento científico frente às problemáticas contemporâneas do comportamento humano e promoção da saúde, impulsionando o desenvolvimento da Psicologia como disciplina e prática profissional. Para tanto, mantemos nosso compromisso, assumido há 10 anos: preservar a diferença e a diversidade da pesquisa científica na Saúde, promovendo sua difusão e refletindo os valores de nosso Programa.

Neste número, nossos leitores terão acesso a pesquisas desenvolvidas em quatro das cinco regiões do Brasil, temos manuscritos assinados no Nordeste, Centro-Oeste, Sudeste e Sul. Apesar de sentirmos falta de nossos(as) colegas estrangeiros e do Norte, estamos satisfeitíssimos com tal pluralidade. Essa diversidade, entretanto, não impactou na confluência de temáticas e espaços de investigação dos(as) pesquisadores(as) que ora publicam na Revista Psicologia e Saúde. Essa confluência nos parece refletir a atualidade da pesquisa científica brasileira, interessada em temas atuais e relevantes.

Em nossa leitura, os artigos que ora se apresentam, embora tenham características comuns que atravessam a vários deles, podem ser encaixados em três eixos: atores sociais, formação em saúde e quadros clínicos. No primeiro, vemos quatro reflexões sobre questões de saúde relacionadas especificamente a diferentes atores sociais, mas com um foco em aspectos vinculados ao sexo e ao gênero das pessoas. Tais estudos nos mostram como há discrepâncias entre aquilo que é preconizado pelas políticas e a realidade nos serviços de saúde, especificamente no que tange à saúde da mulher. Tais reflexões também apontam para o fato de que a atuação dos profissionais de saúde tem impacto em ações de Saúde sobre bebês e, particularmente, sobre o público masculino, população historicamente reticente a práticas de prevenção.

O segundo eixo, formação em saúde, destaca aspectos do ensino e da formação de profissionais para atuação no campo da Saúde. Particularmente, os quatro artigos compreendidos nesse grupo sugerem que há uma pluralidade de inserções didático-profissionais dos estudantes de Psicologia, mas que, no geral das profissões de saúde, faz-se mister uma formação 
científica e humanizada para a atuação na Saúde; inclusive, porque tais elementos levam a impactos na saúde do trabalhador da saúde, oriundo de tal formação.

Por fim, no eixo dos quadros clínicos, temos quatro estudos que operam em diferentes eixos, tais como a drogadição e os espaços das comunidades terapêuticas, o estado da arte do Transtorno de Compulsão Alimentar (TCA), as legislações em saúde e sua relação Transtorno do Espectro Autista (TEA) e a atenção primária em saúde na interface depressão-suicídio.

Diante desse quadro tão rico, convidamos todos(as) à leitura e reflexão!

Rodrigo Lopes Miranda

André Barciela Veras

Arnold Groh

Eric Murillo-Rodríguez José Angel Vera Noriega

Luziane de Fátima Kirchner

Márcio Luis Costa

Paulo Coelho Castelo Branco

Sergio Machado

Sonia Grubits

Editores 